EPISTEME KOINONIA

Revista Electrónica de Ciencias de la Educación, Humanidades, Artes y Bellas Artes

Año II. Vol II. N³.

Enero - Junio, 2019

Hecho el depósito de Ley: FA2018000022

ISSN: 2665-0282

FUNDACIÓN KOINONIA (F.K).

Santa Ana de Coro, Venezuela

Gerfri Hernández

http://dx.doi.org/10.35381/e.k.v2i3.518

\title{
Aspectos teleológicos del hecho educativo: Una aproximación ontoepistemológica
}

\section{Teleological aspects of the educational fact: An ontoepistemological approach}

\author{
Gerfri Hernández \\ gelfrihernandez@gmail.com \\ Asociación Venezolana de Escuelas Católicas, Seccional Falcón \\ Venezuela
}

Recibido: 1 de noviembre de 2018

Aprobado: 1 de diciembre de 2018

\begin{abstract}
RESUMEN
La investigación tiene por finalidad generar una reflexión sobre los Aspectos teleológicos del hecho educativo desde una aproximación onto epistemológica, manejada desde la praxis docente del investigador, es así que mediante el método filosófico de investigación, se ha generado una revisión de documentos que acercan la proposición teórica con la realidad social educativa, por consiguiente no se da por concluido el trabajo investigativo, sino que se generó el inició un análisis profundo sobre la tarea educativa. Educar no es de ninguna manera una función, es ante todo una vocación, una búsqueda profunda de lo humano, una transmisión de vida en sentido estricto y no metafórico. Verificar esta profundidad nos permite pararnos frente al étos educativo con nuevos aires, a tal punto que podemos considerar la educación como parte "esencial", no "accidental" del hombre; es decir, como somos animales racionales, biológicos, sociales, históricos, morales, trascendentes, somos también animales.
\end{abstract}

Descriptores: ciencias de la educación, filosofía de la educación, objetivo educacional, teoría de la educación.

\begin{abstract}
The purpose of the research is to generate a reflection on the teleological aspects of the educational fact from an epistemological onto approach, managed from the researcher's teaching practice, so that through the philosophical method of research, a review of documents that approach the proposition has been generated Theoretical with the educational social reality, therefore, the research work is not terminated, but rather an in-depth analysis of the educational task was initiated. Education is by no means a
\end{abstract}




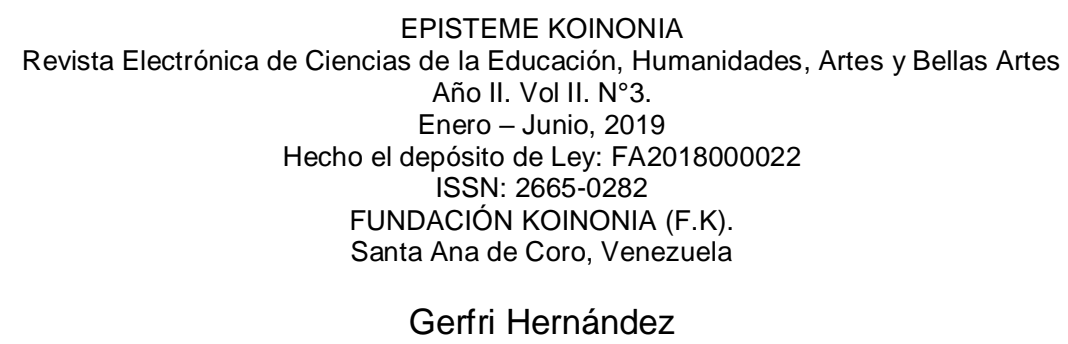

function, it is first and foremost a vocation, a deep search for the human, a transmission of life in a strict and non-metaphorical sense. Verifying this depth allows us to stop in the face of educational events with new airs, to the point that we can consider education as an "essential" part, not an "accidental" part of man; that is, as we are rational, biological, social, historical, moral, transcendent animals, we are also animals.

Descriptors: educational sciences, educational philosophy, educational objectives, educational theory.

\section{PLANTEAMIENTO DEL TEMA}

Se comienza con la explicación del significado "Teleológico". Es la unión de dos palabras griegas ("telos" y "logos") que significan "discurso, tratado, ciencia sobre el fin". Fue acuñada por los primeros filósofos para designar sus tratados sobre el fin del ser, es decir: La razón última de la existencia del ser. En el sentido, como lo usaremos nosotros se debe a Aristóteles quién lo aplica al fin último del hombre, es decir que lo usaremos en sentido ético y por tanto antropológico.

En la actualidad los sistemas políticos usan a su antojo la educación y elaboran políticas que no se adaptan el ser de la educación, sino que pretende mantener el "status questionis", a esto se suma la cantidad de criterios que vienen de la psicología y la sociología así como los que nacen de la misma área de la educación; sin embargo, en la mayoría de las propuestas que leemos a primera vista resultan atrayentes, pero al hacer una lectura más rigurosa no deja de haber algún reduccionismo, por ello, creo necesario ir a las razones de fondo, hay que pasar del Feunomenum (lo que se aparece) al noumenum, lo que llamaban los filósofos griegos "la cosa en sî". Estas reflexiones son fruto de la cátedra Filosofía de la Educación dictada por mi persona en la UPEL en los años 2008 al 2010.

¿Qué tiene que ver esto con nosotros? Mucho. Somos parte del hecho educativo y mucho de lo que hacemos está en orden a un fin, y conviene que sea el mejor. El hecho o fenómeno educativo, no es más que el conjunto de elementos teóricos y prácticos que 
EPISTEME KOINONIA

Revista Electrónica de Ciencias de la Educación, Humanidades, Artes y Bellas Artes

Año II. Vol II. No3.

Enero - Junio, 2019

Hecho el depósito de Ley: FA2018000022

ISSN: 2665-0282

FUNDACIÓN KOINONIA (F.K).

Santa Ana de Coro, Venezuela

Gerfri Hernández

constituyen la realidad que llamamos educación. Es una realidad compleja, que constituye los siguientes elementos:

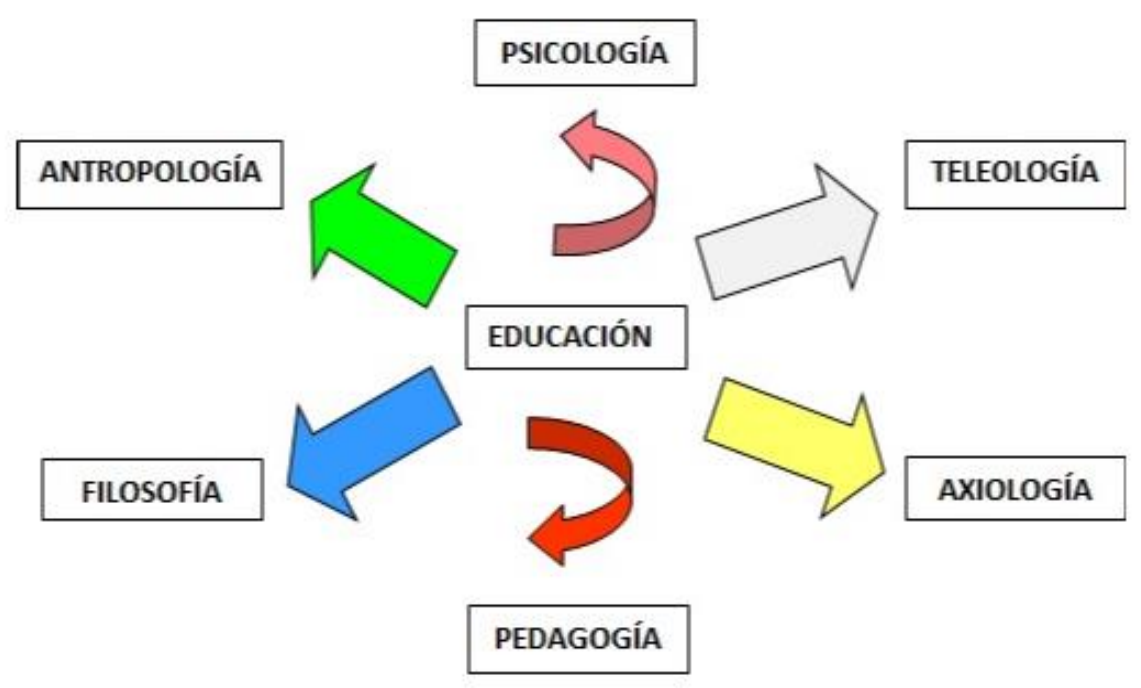

Figura 1.

Elementos de la educación. Elaboración propia.

No me detendré a explicar cada elemento, para poder apuntar a los objetivos planteados para esta exposición. Sugiero para el desarrollo posterior puedan cada uno dedicar tiempo a su estudio. Lo importante a señalar es que no podemos inclinar la balanza hacia uno de ellos, estos deben estar en equilibrio constante no solo en el aula (Praxis educativa), sino también en los planes educativos, en la reflexión sobre la educación y especialmente en la evaluación de nuestro quehacer como educadores. Lo que si nos ocupa es lo filosófico, a lo que dedicare un breve camino, por algunos de los autores más importantes, no implica esto que no tendremos incursiones en otras áreas del saber, pero la fundamentación es básicamente filosófica.

Sócrates (470- a. C.) no escribió, lo que de él se conoce se le debe a los diálogos de Platón, eso originó lo que se llamó e problema de las fuentes, con respecto a la veracidad de estas palabras. El método educativo Socrático era la "mayéutica" o arte de hacer parir; para este filósofo era importante comprender que no era posible enseñar en sentido estricto, a lo más se podía guiar al saber sacando de dentro del otro sus 


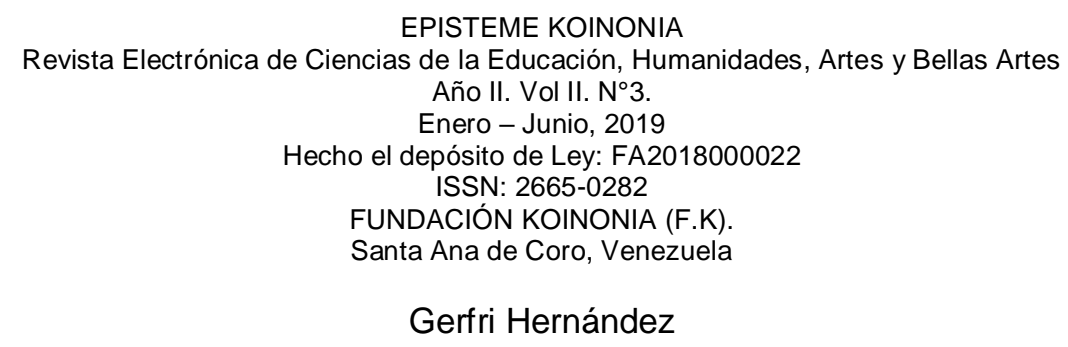

propios conocimientos, en este sentido se entiende la frase famosa de Sócrates "Solo sé que no se nada", no es posible ser maestro, de hecho Sócrates rechazo tal título contraponiéndose a los Sofistas quienes tenían estudiantes y cobraban por el servicio de educar. Para los tres autores de la plenitud de la filosofía griega la virtud es tema central, cada uno con sus matices, para Sócrates se alcana conociéndose, en este sentido, el fin de la educación para este autor es "conócete a ti mismo", podemos decir que Sócrates es el abuelo de la psicología.

Platón (427-347 a. C.) ha sido una de las mentes más abstractas que haya conocido la humanidad, aunque teóricamente haya sido superado, su obra se mantiene intacta en el desarrollo del pensamiento. En su libro la república es donde Platón desarrolla su visión filosófica de la educación, el estado es el responsable de la educación y su fin primordial es el mismo estado y su prolongación en el tiempo, esto se corrobora con la frase: "solo el filósofo, sabio, puede gobernar", en este sentido el sistema ideal es la monarquía, siendo que sería el gobierno del más sabio.

Platón distingue entre la formación filosófica solo para los aventajados, la formación militar y la formación técnica. Pero el gobierno lo deja en manos de filósofo. Distingue una formación distinta para cada clase social: los trabajadores, los guerreros, educación de la juventud. Adquiere también la relevancia de la educación física. Aunque no sea la más atinada, la filosofía de la educación más antigua mejor elaborada es la de Platón, ya que presenta un sistema completo de la misma con sus fines y modos según el modelo estatal.

Aristóteles (384-322 AC) concibió en su libro "Ética a Nicomaco" una estructura fundamental en los seres que los orientaba a todos hacia un fin. La llamo, la estructura finalista. Esta estructura es fundamental para comprender la naturaleza misma de los seres. El fin de una cosa, por ejemplo un instrumento (pincel, escudo, lápiz), es servir para lo que está destinado (pintar, proteger, escribir). En este sentido, cuando un instrumento realiza correctamente el fin para el cual fue concebido, decimos que es bueno; por tanto su perfección está en su bondad (el ser es bueno, en sentido 


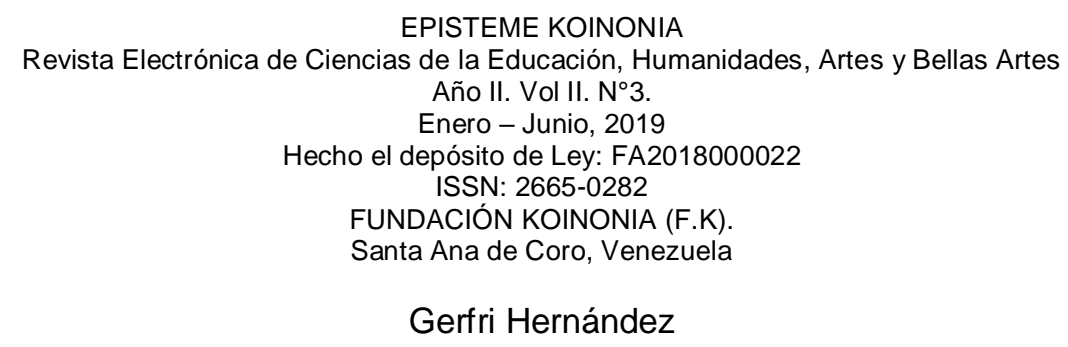

filosófico). El fin de un animal está en su estructura fundamental: Nacer, crecer, reproducirse y morir; prácticamente se observa que su fin está en la supervivencia de la especie, prolongar la especie. Consecuencias mayores tuvo este planteamiento cuando lo aplico al ser humano y explico:

¿Qué es lo que diferencia al hombre se los demás seres? Su racionalidad. El hombre es un animal racional. Aristóteles no llego a definir el fin último del hombre, y esta tarea aún no ha sido resuelta a nivel filosófico. Ha sido resuelta a nivel teológico. Pero del párrafo anterior podemos sacar dos conclusiones básicas en nuestra exposición:

1. La respuesta a la pregunta sobre el fin último del hombre tiene que ver con su racionalidad, es decir, con aquello que lo diferencia y caracteriza, lo que le da su ser propio. ¿Qué implica esa racionalidad? Autoconciencia, individualidad, libertad, responsabilidad ante su vida, capacidad de proyección con lo que implica esto en poder dirigir nuestro destino.

2. En segundo lugar, la respuesta a esta pregunta tiene que ver con el bien, el aspecto más íntimo, que se funda en la capacidad de elegir en libertad. En este aspecto se fundan las leyes positivas y el derecho en general. Al respecto debo decir que estamos acostumbrados a las nociones religiosas y morales de bien. El sentido de bien aquí mencionado es el filosófico y/o ético, hay que entenderlo con vista al ser.

Aristóteles funda, además otra variante del tema, en base a la pregunta ¿Cuál es el fin que persigue todo hombre? Todos coinciden en una cosa: La felicidad. De aquí nace la ética de la felicidad o las llamadas éticas teleológicas. Sin embargo, cuando nos preguntamos ¿Qué es la felicidad? Aquí es donde no es fácil ponerse de acuerdo. Para unos el placer, para otros el poder, para otros el tener, para otros el arte, el deporte. Aristóteles afirma que estas cosas son necesarias pero que no es suficiente, porque muchas personas que se han dirigido por este camino no se notan con frecuencia felices o su felicidad no es permanente. 


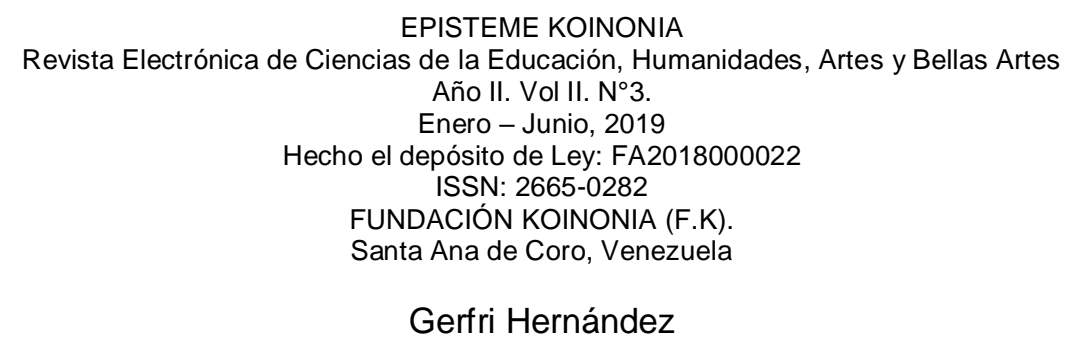

En este sentido, Aristóteles concibe que siendo la razón y el bien iluminadoras en el camino de la felicidad, por tanto está en la virtud. La vida virtuosa, por esto la ética aristotélica es llamada también ética de la virtud que no es otra cosa que vivir según nuestra propia naturaleza racional, en el justo equilibrio. La virtud es fruto del conocimiento de la verdad (aspecto racional) y la vida justa, según la verdad (aspecto ético). Un hombre virtuoso puede disfrutar del placer sin permitir que este lo destruya, puede utilizar el poder de forma equilibrada, es capaz de ser libre.

En conclusión para Aristóteles el fin de la educación es la virtud, con la que viene la felicidad, y estas a su vez son fruto del conocimiento. A diferencia de Platón, Aristóteles muestra no una estructura académica completa, sino el fin, en cuanto al ser del hombre y esto es muy importante, por cuanto a consideración es lo olvidado en los programas educativos actuales.

Quiero destacar un texto antiguo que narra con versátilmente las razones antropológicas más profundas de la educación, especialmente se entiende como necesidad de ser, de existir de vivir. Se trata del texto de Gregorio de Nisa (+379): El Hombre, donde afirma que dentro del universo de los seres creados, al momento del nacimiento, el hombre es uno de los más vulnerables, la necesidad de alimento y protección se hace evidente ya en los primeros momentos de su vida y se prolonga no por pocos años. Los demás animales nacen ya con un pelaje adecuado para cubrirse y pueden ingerir alimento en poco tiempo, así mismo caminan rápidamente.

Pero el hombre nace totalmente desprotegido e indefenso, sin una ayuda sostenida perecería inevitablemente, así mismo, nace no solo con necesidad de quién le de protección y alimento; existe una necesidad mucho mayor, aquella de encontrarse unido a alguien que le enseñe a vivir, que le señale su origen-identidad. Hemos evitado la expresión "necesidad afectiva" ya que la necesidad de la que estamos hablando no sería bien abarcada con esta expresión. Se trata de aprender a vivir, de ser llevado a conquistar su "ser persona". Queda claro de dónde nace la necesidad de la educación. 


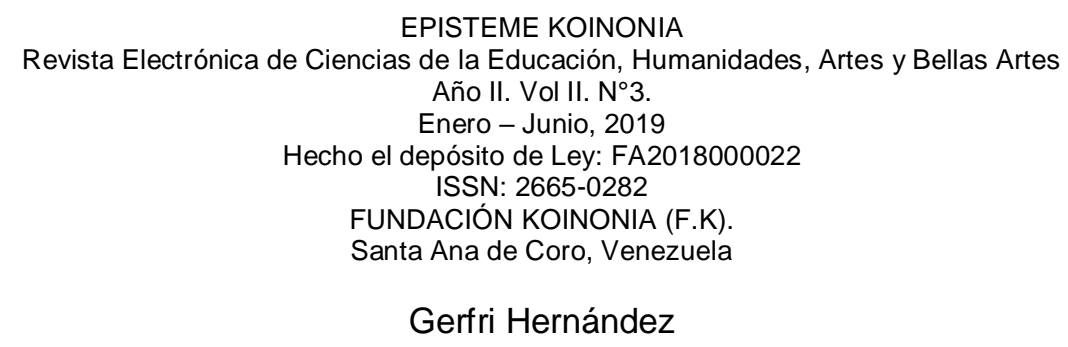

Este es uno de los principales textos antiguos que presenta la educación como hecho antropológico.

Para explicar mejor este pasaje podemos ofrecer un texto muy emotivo del escritor Erich Fromm que explica la expresión bíblica "una tierra que mana leche y miel" explica que la leche se refiere al alimento corporal y a todo aquello que es necesario para cubrir las necesidades perentorias; la miel, por su parte, es el símbolo de la dulzura de la vida y de la felicidad, se trata del amor. En este sentido, la educación la responsabilidad de educar nace del hecho de las necesidades más profundas de "nuestro ser humanos". Conviene a modo de síntesis, mencionar dos representantes clásicos Cristianos de la baja edad media, como son Agustín de Hipona (354-430 d. C.) y Santo Tomas de Aquino (1224-1274), son los grandes maestros de la cristiandad, aunque no trataron directamente el tema de la educación, ambos sustentan la visión cristiana de la educación que domino todo el medioevo hasta el renacimiento. Para la época los fines de la educación son ante todo religioso y moral, conocimiento de Dios con miras a la salvación del alma, el conocimiento y defensa de la doctrina católica. La formación intelectual se reducía solo a los clérigos, considerada la casta dominante, especialmente a los monasterios. La educación católica preservo la documentación en las grandes bibliotecas, pero negó el conocimiento al resto de la humanidad, condenó además cualquier otro tipo de conocimiento que se considerase amenaza.

John Locke (1632 - 1704 d. C.). Tres son los temas de interés de este gran filósofo progresista que ha influido en toda la educación moderna: 1) la necesidad de instaurar la auto - disciplina en los jóvenes, 2) la importancia de razonar con los niños y 3) el significado del desarrollo del carácter en el estudiante; no solamente su intelecto. Para Locke, era necesario sobre todo que el propio estudiante tomara conciencia de su propio proceso, era necesario guiarle hasta que pudiera ver por sí mismo. Dio gran valor a la lúdica dentro del proceso de aprendizaje.

Cabe destacar que la Obra de Locke es amplísima, las ideas de la educación son realmente unas notas en comparación con el resto de su obra, sin embargo tuvo una 


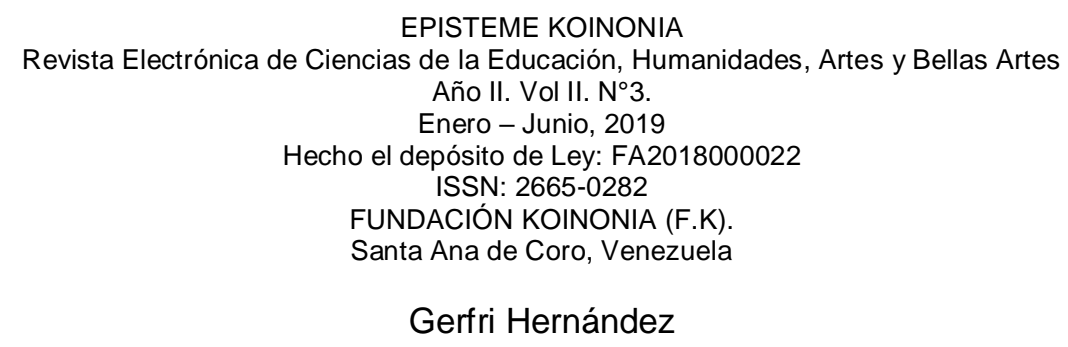

gran influencia en el desarrollo del pensamiento educativo posterior, especialmente el Rousseau, Voltaire y Montesquieu esencialmente porque se oponía al pensamiento rígido de origen eclesial y asumido luego por el estado moderno, en este sentido veía la educación privada como el mejor camino a transitar.

Jean Jacobo Rouseau (1712-1778), en su libro "Emilio" hace una presentación crítica de la educación instituida y una defensa de la educación natural y libre. El educando debe desarrollarse libremente y sin violencia, siguiendo solo su auténtica naturaleza y rechazar todo lo antinatural (costumbre o ley), rechaza en este sentido, la doctrina eclesial del pecado original, afirma que "todo sale bueno de las mano del autor de las cosas, todo se vicia en las manos de los hombres". El Emilio fue un texto también de gran influencia, en especial en el siglo de las luces. El rechazo a toda intervención de fuera (sea estadal-legal o religiosa-moral) en la educación es siempre un principio sano cuando dicha intervención no deja que las propias potencialidades se desarrollen. El fin de la educación en sentido rousseauniano es elevar al máximo potencial la naturaleza humana y para ello es necesario alejarla, cuidarla, defenderla de toda intervención extraña que evite tal fin.

Immanuel Kant (1724 - 1804), otro grande de la educación, aunque descuidado. "el problema más grande y difícil al que el hombre puede dedicarse, es el problema de la educación". Kant apunta a unos elementos importantes dentro de la educación, en primer lugar subraya que solo a través de la educación puede perfeccionarse la naturaleza humana, considera la educación moral como elemento central, en este sentido el deber es la puerta de la vida moral y virtuosa; considera que es necesario examinar filosóficamente las áreas de conocimiento a considerar, pues de lo contrario ¿de qué vale estudiar algo que no tiene sentido estudiar?

John Dewy (1859-1952). Filósofo y pedagogo pragmático estadounidense de tendencia progresista y de gran influencia, quien elabora un sistema completo de la educción, semejante al que Platón, guardando las diferencias:

En tanto la filosofía educativa de Platón descansa sobre su creencia en la 


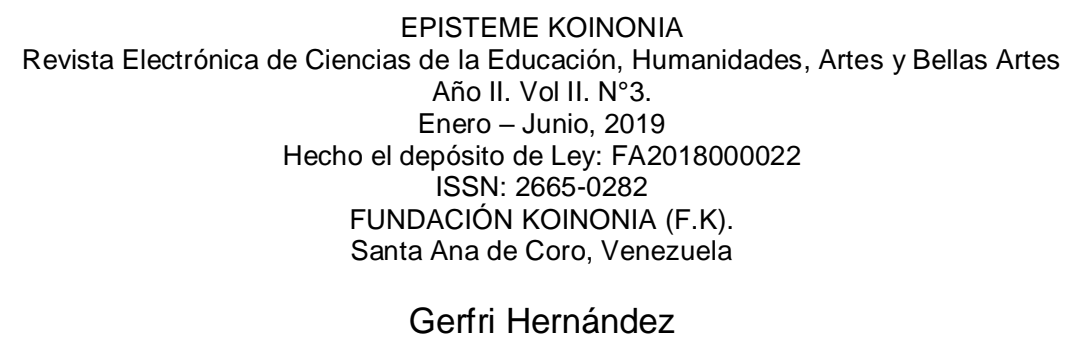

aristocracia y el poder de la razón pura, la filosofía educacional de Dewey se basa en la creencia en la democracia y el poder del método científico

Para este autor el método científico ha de aplicarse no solo a la ciencia, sino a la vida en general. Es ciencia la experiencia que se hace racional. En este sentido, toma valor la verdad de cada uno en lugar de la verdad en sí de la filosofía clásica. Su postra educativa es parecida a la marxista en cuanto busca explotar todas las potencialidades del hombre en la búsqueda de un conocimiento práctico y transformador de la realidad. Alfred North Whitehead (1861-1947). En su propuesta escrita en el libro Los Fines de la Educación, presenta como fin fundamental La sabiduría, en esto se separa de la forma tradicional de adquisición de habilidades mecánicas y de fórmulas establecidas para expresar información.

La finalidad de la educación es infundir sabiduría, la cual consiste en saber usar bien nuestros conocimientos y habilidades. Tener sabiduría es tener cultura y la cultura es la actividad del pensamiento que nos permite estar abiertos a la belleza y a los sentimientos humanitarios.

Whitehead, establece una gran diferencia entre educar y formar, educar seria la búsqueda de lo que él llama sabiduría y que lograría no multiplicando las materias sino educando a fondo en base a conocimientos útiles que vallan con los intereses de los alumnos y formar que sería lo que él llama conocimientos muertos que a la larga no Ilevan nada. La educación debe estar anclada en el aquí y el ahora, "La educación es la adquisición del arte de utilizar los conocimientos. Es un arte muy difícil de impartir...lleva implícito el problema de mantener vivo el conocimiento, de evitar que se vuelva inerte". Este autor distingue que primeros es necesario adquirir el conocimiento para luego utilizarlo, como quien afila una espada para ir a la guerra.

Jacques Maritain (1882 -1973). Filosofó cristiano que considera "la meta final y definitiva en lo que concierne a la educación de una persona, está en su vida personal y en su progreso espiritual, no en su relación con la sociedad y el ambiente". Esta postura parte del humanismo cristiano que ve en el alma humana un elemento espiritual divino, 


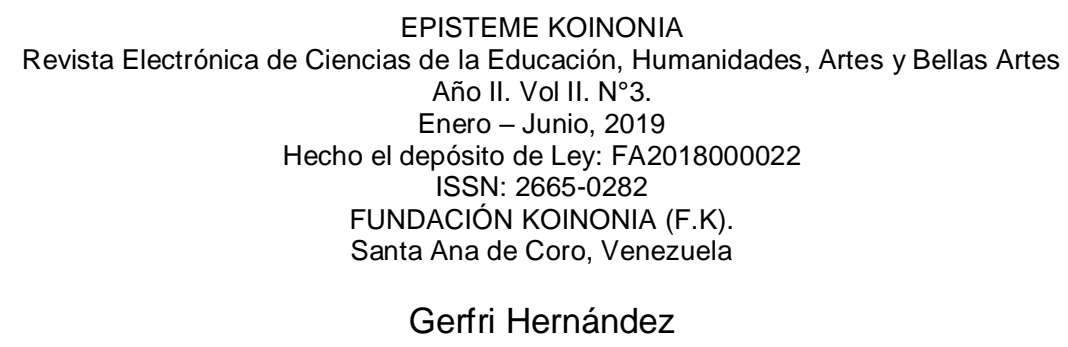

en este sentido es contrario al pragmatismo. Así mismo Maritain valoriza la educación moral como esencial en el crecimiento de la persona.

Convine considerar otros pensadores, quienes aunque no se ganaron el título de filósofos fueron importantes en el desarrollo del pensamiento educativo latinoamericano y venezolano; cabe destacar que no desarrollemos sus planteamientos: Pablo Freire: el fin de la educación es la humanización; Iván Illich, quien apoya una educación libre de cualquier imposición externa, sea estadal, religiosa o moral. Pestalozzi, el fin de la educación es la ida moral, entendida esta como plenitud de la persona. En la vida venezolana encontramos otros pensadores: Simón Rodríguez, Andrés Bello, el maestro Prieto Figueroa, entre otros.

Una vez completado estas consideraciones históricas mostramos en forma de síntesis los fines de la educación, en un intento de aglutinar lo que la tradición filosófica nos ha legado, sin pretender dar por culminado el tema, lo contrario es una síntesis apretada que deja un sabor a más:

\section{FINES DE LA EDUCACIÓN}

\section{Insertar al Hombre en Sociedad}

Aquí se encuentra el fin político social de la educación. En razón de este fin se crean las leyes y los proyectos educativos. Aunque no sea algo que poseamos claro a la hora de realizar un plan educativo (Proyecto pedagógico de aula; un plan de administración y evaluación; una unidad curricular), el rol gregario que posee la educación, especialmente en los primeros años de nuestra vida es fundamental. Tan importante que de ella depende nuestra inserción en sociedad. No por casualidad, a una persona que no pudo alcanzar esta capacidad la llamamos antisocial o desadaptado social. El fin de ellos es bien conocido, en este sentido el desarrollo de la comunicación, es de vital importancia en este ámbito.

Las políticas públicas resultan un elemento de capital importancia en la educación institucional, sin embargo el estado debe cuidar de no involucrarse en lo que respecta a 


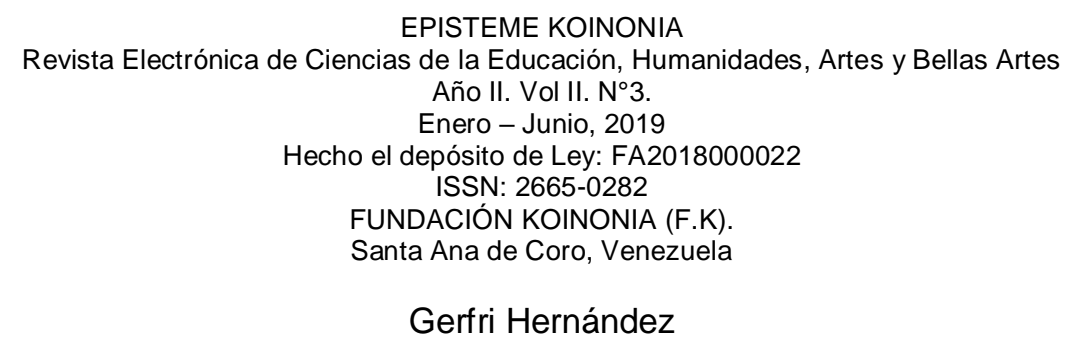

"étos" particular, dicho de otro modo, debe resguardar la intimidad personal, por ejemplo, la educación de los hijos es potestad de los padres, no del estado, pertenece al "étos" privado y no social, por ende se protegerá la libertad de culto, de elección de la escuela, se evitará ante todo la ideologización de la educación, entre otros.

\section{Formar la Persona}

La tarea más sagrada. Siguiendo la idea de Gregorio Nacianceno, presentada en la primera parte, podemos afirmar que al comparar al ser humano con los demás seres de la creación, se encuentran realidades que sorprenden. Por ejemplo, cuando nace una cría de búfalo, es esperado por su manada por tan solo 5 minutos, después de este tiempo este diminuto ser puede alcanzar 20 kilómetros por hora y ya después de pocas horas puede alcanzar el ritmo de la manada. Sorprendente. El ser humano, necesita de mucho tiempo para poder caminar y mucho más para defenderse por sí solo y ser autónomo. La mayoría de los estatutos legales coinciden en que el ser humano es libre y responsable de sus actos (mayor de edad) a los 18 o 21 años. Es bastante tiempo si nos comparamos con el resto de los seres creados. Este es uno de los aspectos filosóficos profundamente antropológicos que expresan la necesidad de ser educados.

A este fin se asocia además, que la mayor parte de nuestra juventud la pasamos en un aula de clase. No existe actividad en la que el ser humano contemporáneo gaste más energía y tiempo que en la educación: sin tomar el tiempo pasado en los maternales 10 2, contamos los 3 años de pre-escolar, 6 años de primaria, 3 de básica, 20 tres (para los técnico medio) media diversificada, 5 para la carrera universitaria, 2 o 3 para posgrado. Suman de 20 a 25 años si no somos aplazados. ¿Por qué tanto tiempo? ¿Cuál es la razón fundamental? La formación de la persona. Algún poeta afirma que nacemos hombres pero nos hacemos personas.

Por otro lado a nivel de oportunidades de vida, es necesario decir, aunque puede haber excepciones, que las personas mejor formadas académicamente asumen más fácilmente la vida, y esto es por los criterios obtenidos en la formación en general, pero 


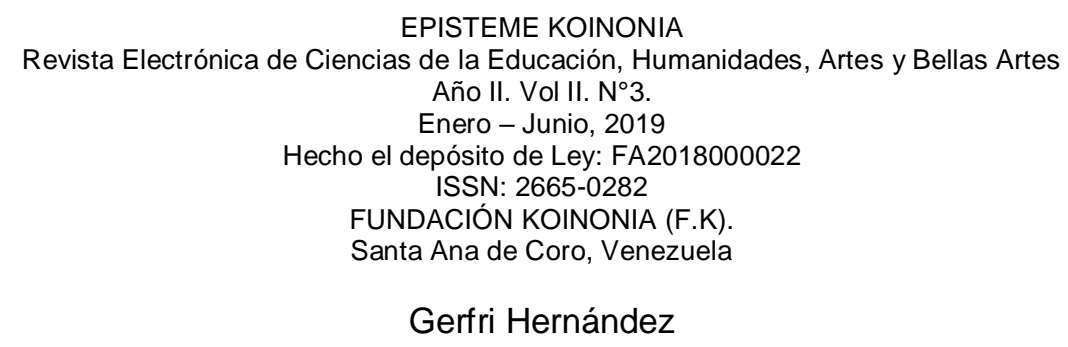

principalmente en la formación académica. Con respecto a los que tienen la tarea y responsabilidad de educar poseen un gran ministerio en mano, el de donar a otro, no solo el conocimiento, sino las posibilidades de vida más adecuadas para su desarrollo, de allí la nobleza de la vocación de maestro.

\section{Transmitir Valores}

El sistema de valores de una sociedad es múltiple por cuanto incluyen todos sus valores culturales: Historia, héroes, valores artísticos e intelectuales, folclore, sistema económico, sistema legal, políticos, costumbres ético - morales, entre otros. Educar es considerado a nivel sociológico como la influencia de la generación adulta sobre la más joven. En los valores subsiste gran parte de las verdades que identifican históricamente a una cultura, transmitirlos es parte del desarrollo educativo. El conocimiento de la propia cultura es básico en el desarrollo de la persona. De allí que se de valor al conocimiento de la propia historia y de la historia de la humanidad. Una educación si valores es igual a la deshumanización. Educar es siempre transmitir lo mejor de lo humano, por ello no es fácil separar la vida académica del desarrollo integral de la persona.

\section{El Cultivo de la Razón}

Llevar a plenitud nuestra naturaleza. La contribución de la persona a la naturaleza humana pasa por el desarrollo intelectual. El cultivo de la razones quizá el objetivo más específico de la educación, pero en el mundo contemporáneo, tan dejado de lado en la educación moderna, tendiente a ser más técnica y práctica, entrada en el ámbito de las nuevas tecnologías, mas visuales y operativas y menos reflexivas y creativas. Si bien un sistema educativo, no solo debe cultivar el intelecto, es también cierto que es a través del intelecto que el hombre da sentido y orden a toda su existencia. Sin pensar en un intelectualismo puro, es importante resaltar la función ordenadora que pesa sobre la razón, en este sentido el cultivo de las artes, el deporte, el desarrollo de la creatividad 


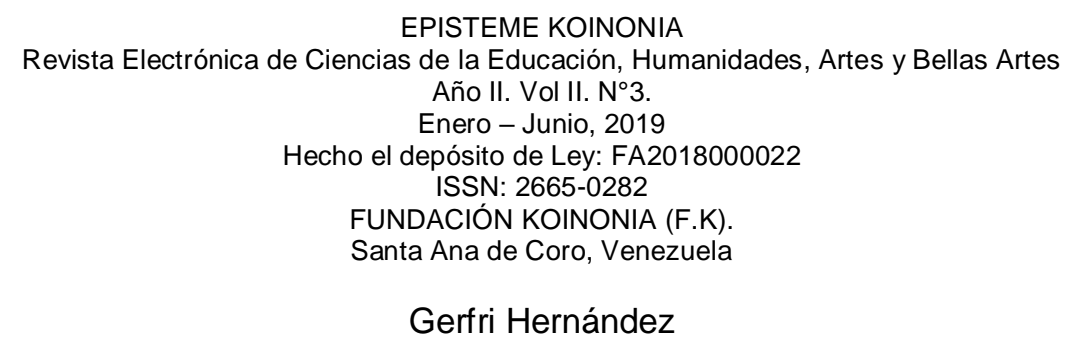

son fundamentales.

Aristóteles cuando define el ser del hombre, afirma que existen varios tipos de almas, vegetativa como la de las plantas, sensitiva que incluye la anterior propia del mundo animal y el alma espiritual, que incluye las anteriores y es propia del hombre, en este sentido define al hombre como animal racional. Es cierto que después, con el paso de la historia se han agregado otras realidades para definir la persona humana, pero la aproximación aristotélica ha resultado insuperable. Cultivar la razón es dedicarse a lo más íntimo de nuestro ser, a aquello que nos hace ser lo que somos, Agustín de Hipona desarrollará su teoría del alma, en base a la noción aristotélica.

\section{El Conocimiento}

A la educación corresponde preparar a la vida a través de la formación de la persona. Donar el conocimiento necesario para que la persona pueda completar su propia historia. Es a través de la educación que la persona se hace partícipe del desarrollo del pensamiento de la humanidad, de sus adelantos, de los pasos que la raza humana a dado y de este modo se inserta en su historia al mismo tiempo que bebiendo de ella le dona su aporte. En este sentido, se trata de donar conocimientos valiosos y verdaderos. Educar es transmitir la verdad de las cosas y de la vida. En este sentido la educación debe ayudar a la persona a dar respuesta a las preguntas existenciales (esenciales) más profundas. Podemos decir que es a través de la educación que el hombre se hace partícipe de la verdad. Es importante en este sentido que los educadores ofrezcan no solo contenidos, sino caminos intelectuales que ubiquen a la persona en la búsqueda de su propia identidad.

\section{Corregir las fallas}

Corresponde, además a la educación corregir las fallas que bien la persona o la humanidad hayan adquirido en el desarrollo de su historia. Aquí se encuentra con propiedad la función ética de la educación, y muchas veces la función más olvidada. 


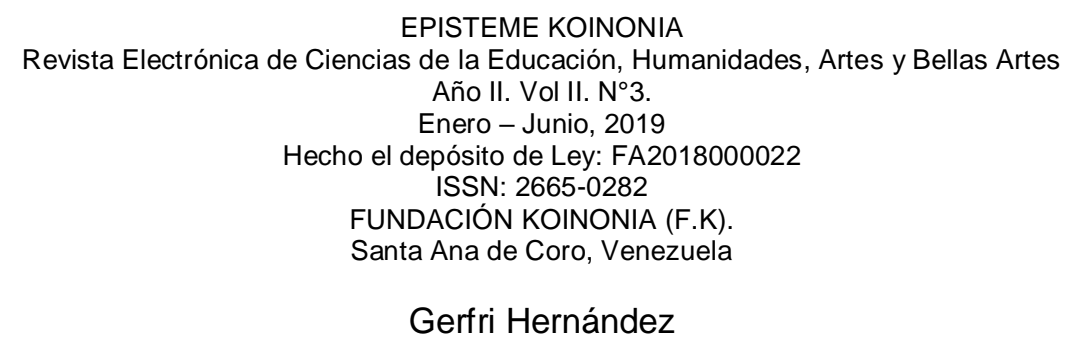

Este elemento otorga dinamismo y movimiento a la enseñanza. En este sentido, de la educación dependen los cambios sustanciales en la sociedad y en el individuo. Las leyes que refieren a la educación deben favorecer esta realidad, aquí el derecho tiene una gran importancia, por cuanto corregir las fallas es una de las funciones primordiales de las leyes. Ofrecer el conocimiento legal en las primeras etapas de la formación es fundamental para ordenar la sociedad en función del bienestar colectivo.

\section{La Felicidad}

Aristóteles presenta su filosofía sobre el bien moral en la Ética a Nicómaco. Su problema esencial es el de los principios éticos ¿En qué consiste la esencia del bien moral? En la eudemonía, era la respuesta que la mayoría de los filósofos griegos comparte, pero aún queda algo por lo cual preguntar ¿Qué es eudemonía? En otras palabras ¿Qué es la felicidad? Es una cosa que todos buscamos pero de la cual hay diversidad de criterios. Para algunos está en el placer y el gozo, pero esto estaría también al alcance del animal y nuestro bien no pasaría de un bienestar corpóreo. Aristóteles descarta varios fines superfluos y coloca la esencia de la eudemonía, y con ello el principio del bien moral, en la perfecta actuación del hombre según su actividad específica. Así como un instrumento que cumple bien su oficio es catalogado de bueno; así mismo el hombre, si se comporta según su naturaleza y cumple los cometidos fundados en su esencia, llenando así el sentido de su ser, le llamamos bueno y al mismo tiempo dichoso.

En este sentido cree Aristóteles que el hombre debe dejarse llevar por su racionalidad, ya que es su apelativo esencial con respecto a otros seres. El fin último ético de todo ser humano, indistintamente del camino elegido o de los fracasos encostrados en el camino, todo hombre actúa en busca de su felicidad, en decir todo hombre actúa en razón del bien.

Si bien la educción ha de servir para todos los propósitos anteriores, ha de servir también para que el hombre sea feliz, no creo haya otra función más excelsa y digna 


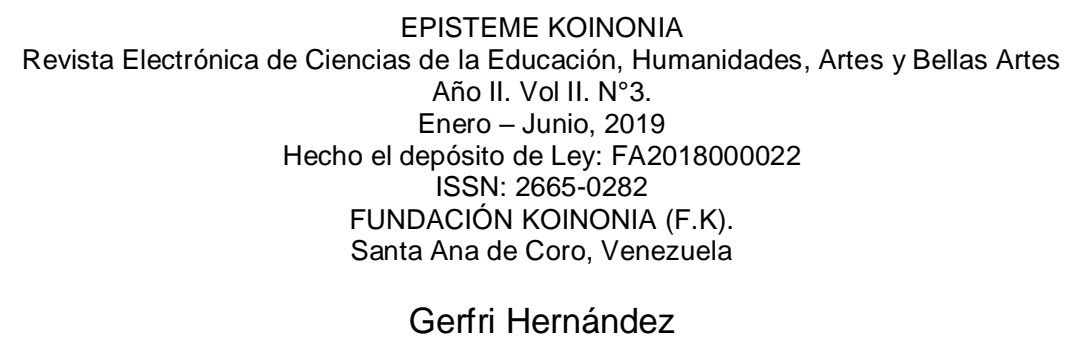

que esta. Con respecto a los que nos dedicamos a la formación de otros no se nos puede olvidar semejante función, por cuanto muchos de los que tendremos al frente necesitan ser puestos en el camino a la felicidad, de lo contrario quizá no la conseguirán. La felicidad de un individuo es una tarea difícil y pasa por nuestras manos. A mayor persona mayor felicidad. A mayor formación mayor posibilidades de vida, de creatividad, de felicidad.

\section{La trascendencia}

Apartando el tema de las distintas visiones religiosas, para evitar susceptibilidades, veo conveniente presentar un séptimo fin de la educación, es el que busca algo inmerso en la condición humana, la trascendencia, bien sea trascender a si mismo con las obras como los grandes personajes de la historia o bien trascender al modo como lo entienden las religiones. Sea de un lado o de otro, la educación debe mostrar este potencial humano equivalente a ser o dedicarse a algo que supera su propia finitud.

La auto trascendencia es posible por la naturaleza espiritual de la persona que la hace consiente de sí misma (autoconciencia). La autoconciencia "es un dato estructural natural de la espiritualidad, mientras que el autodominio está constituido por un acto de la libertad. La autoconciencia es la condición remota del autodominio". Otro elemento entra en juego en la dinámica imperativa de la voluntad sobre los diversos dinamismos, se trata del conocimiento intelectivo y racional, y esto porque es solo la razón la que puede ver la distancia que existe entre un bien particular y el bien en sí (en sentido moral). Solo después de este reconocimiento, cuando es detenida la fuerza motora y motivante de los dinamismos no espirituales; además, solo en este sentido, podemos decir que ha ocurrido, la auto trascendencia.

Transcender es parte de la dinámica del espíritu humano, que no se conforma con la finitud, ni la caducidad. En el fondo el espíritu humano se niega a morir, y por ende, a ser imperfecto. Así la trascendencia brinda al espíritu humano el potencial para alcanzar 


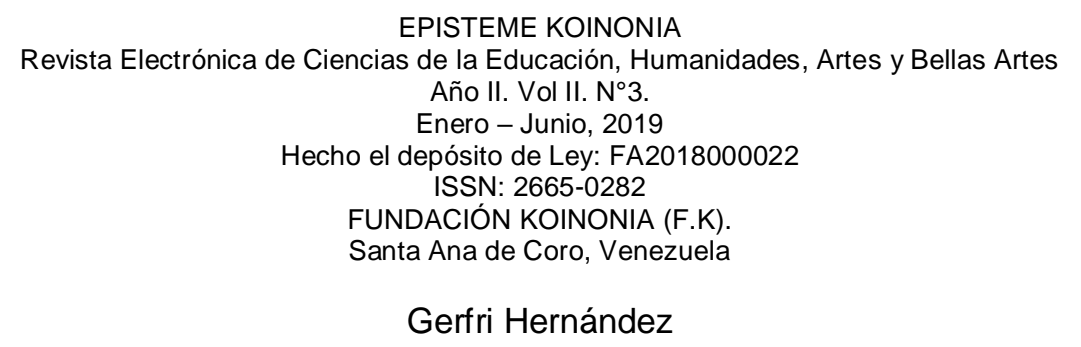

la razón de su ser, lo que le permite acercarse a responder sus preguntas fundamentales.

\section{A MODO DE CONCLUSIÓN}

Este no es un tema para concluir, sino para iniciar una reflexión profunda sobre la tarea educativa. Digo tarea para evocar el sentido de la vocación, rechazar la visión de la educación como mera tarea, trabajo o labor. Educar no es de ninguna manera una función, es ante todo una vocación, una búsqueda profunda de lo humano, una transmisión de vida en sentido estricto y no metafórico. Verificar esta profundidad nos permite pararnos frente al étos educativo con nuevos aires. Además, nos permite valorar lo que somos como educadores, a tal punto que podemos considerar la educación como parte "esencial", no "accidental" del hombre; es decir, como somos animales racionales, biológicos, sociales, históricos, morales, trascendentes, somos también animales

La praxis educativa, vista desde su profundidad filosófica resulta más dinámica, más completa y más hermosa y hace que nuestra labor trascienda a la mera praxis. Quien educa trata lo más hermoso y digno del espíritu humano, navega en un agua sagrada y retoma el sentido de la propia trascendencia en el otro. Quien educa da el ser, hace parir la persona, dona lo que nos hace humanos, seres sociales e históricos. Ofrece la luz del cielo a un mundo de oscuridad.

\section{REFERENCIAS}

1. Aristóteles. De Partibus Animalium, A, 1; 641a 17b 10.

2. Aristóteles. Éthica ad Nicomachum, A 6 y 9.

3. Aristóteles. Ética Nicomáquea; Ética Eufemia, int. Emilio Lledó Iñigo; tr. y no. Julio Pallí Bonet, Gredos, Madrid 1985. 


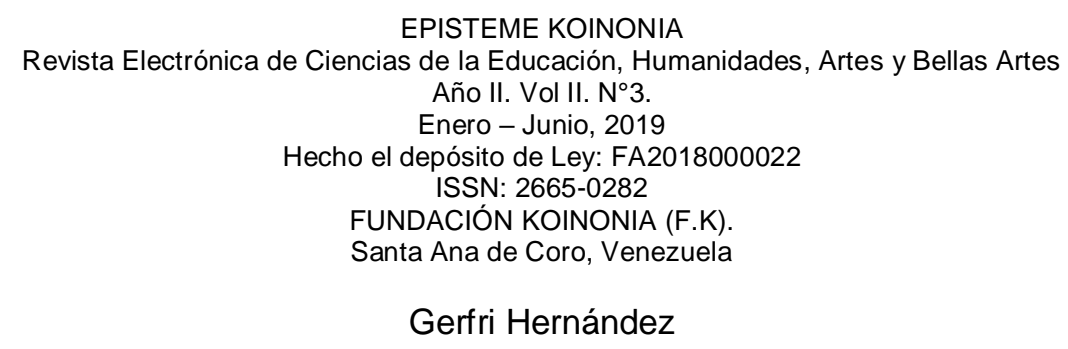

4. Fromm, E. El arte de amar, 41ss; citado por: J. PIEPER, Las virtudes fundamentales, pp. 447-448.

5. Hernández Carballido F. A. (2004).Los Fines de la Educación. Educar para la Sabiduría: Propuesta de Alfred North.

6. Hirschberger J. (1997). Ob. Cit. (tomo II), p. 126.

7. Hirschberger J (1997). Historia de la Filosofía. Antigüedad, Edad Media, Renacimiento (tomo I). Barcelona, Herder. Pp 85-145.

8. Hi Gregorio Di Nissa, L'uomo, n. 7, tr. e int. a cura di Bruno Salmona, CittaNuova, Roma 1982, pp. 135.

9. Illich, I. (2011). Fines de la educación. Recuperado a partir de http://peducativas.blogspot.com/2011/09/fines-de-la-educacion-segun-ivanillich.html

10. Kaffarra C. (2006). Ética general de la sexualidad, tr. es.: Juan José GarciaNorro, EIU, Madrid: Ediciones internacionales Universitarias, p. 35

11. Kuhlemann G., Dr. Brühlmeier A. y Grundel R. (2005). Pensamientos Fundamentales. Educación/formación [contenido en línea]. Disponible: http://www.heinrichpestalozzi.de/es/home heinrich pestalozziinfo/pensamientos fundamentales/ed ucacion formacion/index.htm

12. Locke, J. (1927). Algunos Pensamientos Sobre la Educación.

13. Platón. Dialogo Menon. Presentado por Azcárate F. (1871), tomo 4. Madrid: Medina y Navarro, pp. 283-345.

14. Platón. Dialogo Pitágoras. Obras completas, edición de Patricio de Azcárate, tomo 2, Madrid 1871.

15. Platón. La República. Medina Y Navarro (Ed) (1872). Obras completas, tomo 7, Madrid: edición de Patricio de Azcárate.

16. Rousseau, J. (1762). Emilio. Biblioteca EDAF 33. EDAF. Madrid: Jorge Juan. 
EPISTEME KOINONIA
Revista Electrónica de Ciencias de la Educación, Humanidades, Artes y Bellas Artes
Año II. Vol II. N³.
Enero - Junio, 2019
Hecho el depósito de Ley: FA2018000022
ISSN: 2665-0282
FUNDACIÓN KOINONIA (F.K).
Santa Ana de Coro, Venezuela
Gerfri Hernández

17. Vargas-Mendoza, J. E. (2007). Fundamentos filosóficos de la educación: Apuntes para un seminario. México: Asociación Oaxaqueña de Psicología A.C.

18. Whitehead, A. (1957). Los fines de la educación. Buenos Aires: Paidos.

19. Whitehead. Revista Digital Universitaria [Revista en línea], Volumen 5 Número 1, 31 enero 2004.Disponible: http://www.revista.unam.mx/vol.5/num1/art5/portada.htm [Consulta: 25, febrero 2016]

20. Whitehead, A. (1957). Ob. Cit., p. 20.

C2019 por el autor. Este artículo es de acceso abierto y distribuido según los términos y condiciones de la licencia Creative Commons Atribución-NoComercial-Compartirlgual 4.0 Internacional (CC BY-NC-SA 4.0)

(https://creativecommons.org/licenses/by-nc-sa/4.0/). 